\title{
CAPITAL CULTURAL E CONSUMO DE BENS CULTURAIS EM FAMÍLIAS NUCLEARES
}

\section{CULTURAL CAPITAL AND THE CONSUMPTION OF CULTURAL GOODS IN NUCLEAR FAMILIES}

\author{
Gilberto Venâncio Luiz \\ Universidade Federal de Viçosa - Campus Rio Paranaíba - MG \\ gilberto.luiz@ufv.br
}

Karla Maria Damiano Teixeira Departamento de Economia Doméstica, da Universidade Federal de Viçosa - Campus Viçosa/MG kdamiano@ufv.br

Neuza Maria da Silva Departamento de Economia Doméstica, da Universidade Federal de Viçosa - Campus $\mathrm{Viçosa/MG}$ neuza@ufv.br

Neuza Maria da Silva Departamento de Economia Doméstica, da Universidade Federal de Viçosa - Campus Viçosa/MG neuza@ufv.br

Francismara Fernandes Guerra Departamento de Economia Doméstica, da Universidade Federal de Viçosa - Campus Viçosa/MG francismarafernandes@yahoo.com.br

Submissão: $16 / 10 / 2018$ Aprovação: 19/12/2018 


\title{
RESUMO
}

O objetivo deste trabalho foi verificar a relação entre variáveis sociodemográficas e o capital cultural das famílias nucleares brasileiras com as despesas relacionadas ao consumo de bens e serviços culturais. A base de dados utilizada foi a Pesquisa de Orçamentos Familiares período de 2008/2009, realizada pelo Instituto Brasileiro de Geografia e Estatística (IBGE), sendo a amostra de 27.479 domicílios selecionados com base na estrutura familiar nuclear com presença de filhos em idade escolar. Para análise dos dados, utilizaram-se análise de regressão múltipla e coeficiente de correlação. Os resultados evidenciaram relação positiva entre a renda per capita familiar, o número de pessoas na família, o capital cultural e a idade do cônjuge com os gastos com bens e serviços culturais. De acordo com o modelo proposto, a renda per capita e o capital cultural foram as principais variáveis explicativas dos gastos com bens e serviços culturais das famílias.

Palavras-chave: Consumo. Famílias nucleares. Capital cultural. Bens culturais.

\begin{abstract}
The objective of this study was to determine the relationship between sociodemographic variables and the cultural capital of Brazilian nuclear families with their expenditure on the consumption of cultural goods and services. The Consumer Expenditure Survey (2008/2009) conducted by the Brazilian Institute of Geography and Statistics (IBGE) was used as database. The sample consisted of 27,479 households that were selected based on the nuclear family structure with school-age children. Data was analyzed using multiple regression analysis and correlation coefficient. The results showed a positive relationship between income per capita, number of people in the family, cultural capital and age of the spouse/husband with the expenditure on cultural goods and services. According to the model, income per capita and cultural capital were the main explanatory variables of the expenses with cultural goods and services in the households.
\end{abstract}

Keywords: Consumption. Nuclear families. Cultural capital. Cultural goods. 


\section{INTRODUÇÃO}

O consumo de bens e serviços culturais pode ser considerado importante elemento para o desenvolvimento socioeconômico à medida que amplia as capacidades criativas e expressivas do indivíduo e estimula a coesão social, sendo uma das formas pelas quais a cidadania se expressa (PAGLIOTO; MACHADO, 2012). Segundo Bourdieu (1998, p. 67), o "capital cultural é um conjunto de recursos atuais ou potenciais que estão ligados à posse de uma rede duradoura de relações mais ou menos institucionalizadas de interconhecimento e interreconhecimento" ou, em outros termos, estão vinculados a um grupo, como um conjunto de agentes unidos por ligações permanentes e úteis.

Existem evidências de que o maior acesso a bens culturais melhora a qualidade de vida dos membros de uma coletividade, tal que uma política cultural que se limita a fomentar o consumo de bens culturais importados tende a ser inibidora de atividades criativas e a impor barreiras à inovação. Em uma época de intensa comercialização de todas as dimensões da vida social, o objetivo central de uma política cultural deve ser a liberação das forças criativas da sociedade. Não se trata de monitorar a atividade criativa e, sim, abrir espaço para que ela floresça (ARBIX; ZILBOVICUS; ABRAMOVAY, 2001).

Os atos de consumo fazem parte da constituição do indivíduo e daquilo que ele pretende projetar a respeito de si mesmo, gerando padrões de consumo. Esses padrões, de acordo com Ponte e Mattoso (2014), podem variar em função do capital cultural de cada indivíduo, por meio de uma variedade de dimensões. Holt (1998) destacou o capital cultural, em todos os campos sociais, como importante recurso na vida das pessoas; no campo de consumo, ele atua de forma a converter esse recurso em gostos e práticas de consumo. Os produtos funcionam, portanto, como representações das práticas de consumo, gerando a distinção e evidenciando a posição social do consumidor. Dessa forma, o capital cultural é um dos elementos relevantes para auxiliar no estudo do consumo particular de produtos e serviços culturais.

Segundo Silva, Araújo e Souza (2007), analisando os dados da Pesquisa de Orçamento Familiar (POF) 2002/2003, os gastos culturais foram de $\mathrm{R} \$ 31,9$ bilhões, perfazendo um total de $3 \%$ dos gastos anuais das famílias brasileiras e cerca de 2,4\% do PIB nacional. Desses $3 \%$ totais, $82 \%$ referiam-se ao consumo de bens e serviços culturais dentro do domicílio, ou seja, televisão, vídeo, música e leitura. O consumo que pressupõe a saída do domicílio (cinema, teatro, shows) correspondeu a 17,8\%. As despesas culturais demandam equipamentos e uso de bens duráveis, correspondendo a $45,8 \%$ do total.

Na pesquisa sobre o tema consumo de bens culturais pelas famílias brasileiras, pode-se verificar que pouco se tem dedicado ao estudo desse tipo de consumo, principalmente quando relacionado com o capital cultural das famílias. Os trabalhos têm enfoque em questões demográficas e econômicas (Diniz e Machado, 2011; Silva, Araújo e Souza, 2007; Seiblitz, Bonifácio e Ayres, 2013) ou em consumidores individuais (Paglioto e Machado, 2012; Ponte e Mattoso, 2014). Nesse contexto, este trabalho tem como objetivo verificar a relação entre variáveis sociodemográficas e o capital cultural das famílias nucleares brasileiras com as despesas ligadas ao consumo de bens e serviços culturais. Por família nuclear, entende-se o grupo familiar composto por esposa e esposo, com ou sem filhos.

Entender as variáveis que influenciam os gastos das famílias não é tarefa fácil, devido à multiplicidade de elementos que devem ser considerados. Dessa forma, o estudo do consumo de bens culturais pelas famílias brasileiras e de suas variáveis sociodemográficas e de como o capital cultural da família influencia esse consumo é de grande importância para o entendimento da sua influência no cotidiano familiar. Isso porque, conforme descrito por Silva, Araújo e Souza (2007), o consumo de bens culturais tem grande impacto na economia brasileira, bem como perfaz percentual significativo dos gastos das famílias. 


\section{TEORIA DO CAPITAL CULTURAL}

O termo capital cultural foi cunhado por Pierre Bourdieu e formalizado, inicialmente, com a colaboração de Jean-Claude Passeron na obra Leshéritiers, publicada em 1964. A Teoria do Capital Cultural foi desenvolvida a partir de suas observações acerca dos mecanismos responsáveis pelas desigualdades no aproveitamento e rendimento de estudantes pertencentes a diferentes grupos sociais. Assim, o capital cultural constitui o elemento da herança familiar que teria o maior impacto na definição do destino escolar (ALMEIDA CUNHA, 2007).

Conforme descreveu Bourdieu (1998), há três tipos de capital: o econômico, o social e o cultural. O capital cultural difere do capital econômico (recursos financeiros) e do capital social (relacionamentos, filiações a instituições e rede de relacionamentos). O capital cultural é produto das aprendizagens sem intenção, tornando possível uma disposição adquirida por meio da aquisição familiar da cultura legítima. Em relação à obtenção junto com a família, isso se dá pelo nível educacional ou pelo trabalho exercido pelos pais em interação com famílias semelhantes, estimulando o pensamento, a construção do senso crítico e o desenvolvimento de habilidades de comunicação que viabilizam a aquisição constante de novos conhecimentos e habilidades, com ênfase na produção simbólica (HOLT, 2010).

Royal (2012) definiu o capital cultural como as normas e valores que as pessoas vão levar inconscientemente por toda a vida. São, muitas vezes, os valores incorporados ao longo da infância e da educação que formam a compreensão e comportamentos ao longo da vida. Esse autor argumentou que a educação continua sob a influência dos pais, que imbuem em cada indivíduo o conhecimento de seu lugar na sociedade e que papéis ele pode desempenhar e que atividades, tanto de lazer quanto de trabalho, ele pode realizar. O capital cultural consiste na familiaridade com a cultura dominante em uma sociedade e, especialmente, a capacidade de compreender e utilizar a linguagem polida. A posse de capital cultural varia de acordo com a classe social, no entanto o sistema de ensino assume a posse de capital cultural (SULLIVAN, 2001).

O ensaio mais famoso de Bourdieu que trata sobre o Capital Cultural, "The Forms of Capital", concentra-se no habitus e indica que o capital cultural pode ser encontrado em três formas diferentes: (a) como um estado encarnado, com base em disposições duradouras da mente e do corpo. Mas isso se refere ao habitus como um conjunto de gostos e competências de julgamento. Esta forma de capital cultural é, em grande parte, herdada ou, mais precisamente, adquirida através da educação refinada em uma casa. (b) O Capital Cultural pode ser medido também como atitudes, preferências e competências. Tem um estado objetivado, sob a forma de bens culturais - O que poderia ser coleções de livros ou instrumentos musicais? Esses produtos irão refletir o habitus e podem ser observados ou relatados em pesquisas. (c) O capital cultural também existe em um estado institucionalizado (por exemplo: escolas, universidades, escolas técnicas), que em primeiro lugar diz respeito a qualificações educacionais dos indivíduos (PRIEUR; SAVAGE, 2011).

O capital cultural enquanto habitus não vai muito além da ideia da existência de uma subcultura de classe que auxilia o processo de reprodução social. Seu conceito também é utilizado numa acepção um pouco diferente. Capital cultural indica acesso a conhecimento e informações ligados a uma cultura específica, aquela que é considerada como a mais legítima ou superior pela sociedade como um todo. Assim, aqueles que têm acesso a esse capital cultural, a essas informações, terão maior valor, mais "distinção", assim como acesso facilitado a outros recursos escassos. Nessa acepção, o conceito de capital cultural deixa de ser apenas uma subcultura de classe e passa a ser uma estratégia, um instrumento de poder (BOURDIEU, 1998). 
Nessa mesma perspectiva, destaca-se que o capital cultural pode ser apresentado de três formas: incorporado, via conhecimentos implícitos, habilidades e disposições; objetivado, como um produto cultural; e institucionalizado, através de certificados e diplomas oficiais que comprovem a sua existência. Dessa maneira, o capital cultural incorpora o papel de distinção em diversos campos e não somente nas artes, visto que opera nos múltiplos campos de consumo, como comida, decoração, moda, cultura popular e esportes (BOURDIEU, 1998; HOLT, 1998). Em relação a essas três formas, os recursos que compõem o capital cultural podem ser acumulados por três tipos primários de aculturação: Educação familiar mensurada pela educação e ocupação do pai, uma vez que o status da família tem o domínio do pai; Educação formal - retrata o nível de educação do próprio consumidor; e Cultura ocupacional - apresenta a ocupação do consumidor (BOURDIEU, 2011; HOLT, 1998; SILVA, 2008).

A educação é um componente importante do capital cultural, uma vez que contribui para a capacidade do indivíduo para o processamento e aquisição de informações. A escolaridade dos pais também é fator relevante, pois pode ser considerada uma proxy para a exposição aos bens culturais na infância e na adolescência. Espera-se que o efeito desse tipo de educação sobre o consumo de bens culturais seja maior do que o impacto da educação formal, pois indica uma escolha voluntária do indivíduo para a acumulação de capital cultural específico (DINIZ; MACHADO, 2011).

$\mathrm{O}$ conceito de capital cultural configura-se como tentativa de desenvolver uma estrutura teórica para examinar o padrão social do consumo no crescente e mistificado mundo social (HOLT, 1998; SILVA, 2008). Isso porque a classificação do consumidor, conforme o recurso do capital cultural, permite explicar fatores do consumo cultural de forma mais acentuada. A compreensão de quais ordenamentos regem suas escolhas de consumo é muito importante para o entendimento do comportamento de consumo. Um desses ordenamentos é a busca de status que intermedeia a construção de identidades e a ocupação de posição social. Em relação a esse status, o capital cultural atua como fator determinante, convertendo-se em gostos e práticas de consumo. Interessante "é perceber que, entre as fontes de formação de capital cultural, está a ascendência, estabelecendo, assim, uma espécie de herança cultural dos indivíduos que molda seus gostos e práticas de consumo" (PONTE; MATTOSO, 2014, p. 30).

\section{CONSUMO DE BENS CULTURAIS}

Diniz e Machado (2011), estudando os determinantes do consumo de bens artísticoculturais e serviços no Brasil, constataram que o consumo cultural-artístico é desigualmente distribuído na população, sendo determinado, principalmente, pela educação e pela renda. Essas variáveis indicam a posição social dos indivíduos, em que aqueles com ensino superior e renda maior tendem a apresentar maior exposição a bens artístico-culturais, devido a práticas individuais e, ou, familiares, razão por que esses grupos sociais têm melhor acesso a esses bens. Por sua vez, as divergências regionais parecem afetar as despesas de forma mais intensa entre as famílias que gastam mais. Segundo esses autores, os resultados sugerem que as variáveis geográficas influenciam mais o consumo do que características individuais do consumidor.

Silva, Araújo e Souza (2007) verificaram que há heterogeneidade de consumo cultural no Brasil. Nesse tipo de consumo, os indivíduos valorizam a cultura como elemento que organiza informações e interações sociais. Observou-se que a televisão é o produto mais consumido em relação ao lazer, com presença quase universal nos domicílios. Nas grandes regiões metropolitanas do Brasil, cerca de $50 \%$ do montante dos gastos culturais é feito pelos dois decis mais ricos em renda. No entanto, a proporção dos gastos das famílias gira em torno de 3\%, com ligeiras oscilações para mais ou para menos. Esses mesmos autores relataram que 
as famílias cuja pessoa de referência é negra, ou mulher, consomem muito menos bens culturais, num claro reflexo das interações e desigualdades fundadas no gênero e na etnia (cor/raça).

Em um recorte entre zonas rural e urbana, Seiblitz, Bonifácio e Ayres (2013) verificaram que o consumo de bens e serviços culturais e recreativos das famílias da zona urbana foi maior em relação ao das famílias da zona rural. Os dados indicam também a existência de diferença significativa no gasto com recreação e cultura entre áreas urbanas e rurais, da mesma forma como ocorre entre as regiões geográficas. Os citados autores concluíram que essa diferença entre as regiões pode estar relacionada, entre outras coisas, à quantidade disponível de bens recreativos e culturais e com o nível de renda de cada região.

Analisando o perfil dos frequentadores de atividades culturais nas metrópoles brasileiras, Paglioto e Machado (2012) identificaram que no tocante ao consumo de bens culturais, ainda que exista diversidade cultural, o acesso à cultura foi ampliado nos últimos anos, no âmbito das atividades culturais privadas desenvolvidas em suas diversas modalidades, como museus, salas de cinema, teatros, entre outros. Há uma concentração em determinada parcela da população, caracterizada por um perfil demográfico, educacional e econômico, como também pelas condições de oferta dentro do contexto regional em que os indivíduos estão inseridos.

Segundo Paglioto e Machado (2012), aqueles indivíduos mais abastados gastam mais com cultura fora do domicílio e o fazem para aquisição de ingressos para cinema, shows e teatros. As classes mais pobres, quando gastam com cultura fora do domicílio, o fazem com cinema. Esses mesmos autores identificaram aumento no consumo de bens duráveis televisão, computador - complementares ao dispêndio com cultura dentro do domicílio. Tais gastos aumentaram em número de domicílios que passaram a possuí-los, como também no montante gasto dos que já os tinham. Contudo, esse crescimento aconteceu, especialmente, entre os domicílios que não gastaram com atividades culturais externas.

Em recente estudo, Ponte e Mattoso (2014), analisando a relação dos bens culturais com o capital cultural das mulheres da nova classe $\mathrm{C}$, chegaram a dois grupos distintos: Alto Capital Cultural (ACC) e Baixo Capital Cultural (BCC). Uma das conclusões dessas autoras foi a existência de forte relação entre o nível de capital cultural e o consumo de produtos culturais. Dessa maneira, o consumo desses produtos é capital para a constituição das estratégias de consumo de status dessas mulheres, principalmente quando se trata das categorias audiovisual e microinformática, que exercem papel primordial nessas estratégias nos dois grupos de entrevistadas. Além disso, as citadas autoras identificaram que os produtos férias, leitura e fonografia são relevantes apenas para as mulheres do grupo ACC.

Por fim, Segundo Paglioto e Machado (2007), o consumo de bens e serviços artísticoculturais aumenta as capacidades criativas e expressivas do indivíduo, estimula a coesão social e se torna uma forma de expressar a cidadania. Além do mais, pode servir de base para o desenvolvimento de políticas públicas que promovam o acesso a bens e serviços culturais fora do domicílio pelas camadas mais pobres, visto que esse acesso externo (cinema, teatros, museus), segundo aqueles mesmos autores, é elitizado e inibe o acesso de indivíduos mais pobres.

\section{PROCEDIMENTOS METODOLÓGICOS}

Este trabalho se caracteriza como uma pesquisa quantitativa descritiva transversal, visto que busca verificar as relações entre variáveis sociodemográficas das famílias, o capital cultural e os gastos das famílias com bens culturais; e transversal, devido ao fato de a análise dos dados ser feita em período específico do tempo. Como base de dados, utilizou-se a Pesquisa de Orçamento Familiar (POF), realizada pelo Instituto Brasileiro de Geografia e 
Estatística (IBGE), referente ao período de 2008/2009, que é pública e pode ser acessada no site oficial do Instituto. Essa escolha se deu devido ao fato de até o fim de 2017 não ter sido realizada outra POF.

Os dados foram extraídos dos microdados da POF (2008-2009), obtendo-se uma amostra de 55.970 domicílios. A partir deste quantitativo, foi feita uma verificação de domicílios com falta de dados para variáveis do perfil e dos gastos. Também, foi realizada uma seleção dos domicílios, escolhendo-se aqueles com estrutura familiar nuclear com presença de filhos em idade escolar e que estavam residindo na unidade familiar. A opção de famílias do tipo nuclear foi devida ao fato de o modelo de cálculo do índice de capital cultural ser dado pela escolaridade e pela profissão do pai e da mãe. No final, chegou-se a uma amostra de 27.479 domicílios.

\subsection{Variáveis sociodemográficas}

As variáveis sociodemográficas utilizadas na análise foram: sexo (pessoa de referência da família e do cônjuge), idade (pessoa de referência, cônjuge), anos de estudo, pessoa de referência, cônjuge, número de pessoas na família, renda familiar per capita anual e cor da pele (pessoa de referência, cônjuge).

\subsection{Bens e serviços culturais}

Para definição dos bens culturais deste trabalho, foi usada a classificação adotada no Brasil, que tem como base a Pesquisa de Orçamentos Familiares (POF), desenvolvida pelo IBGE. Segundo Ponte (2012), essa classificação considera, para avaliação, produtos culturais que se relacionem com as necessidades materiais e culturais, úteis para proporcionarem informações, entretenimento, e que possam posicionar socialmente os consumidores dos produtos. Dessa maneira, os produtos culturais foram classificados de acordo com as características, nas seguintes categorias:

1) Leitura: composto por livros didáticos e não didáticos, jornais, revistas e demais produtos da mídia escrita.

2) Fonografia: composto por CDs, discos de vinil, aparelhos e equipamentos.

3) Espetáculo ao vivo e artes: composto por circo, teatro, balé, museu, shows e música.

4) Audiovisual: composto por cinema, práticas amadoras, TV a cabo, equipamentos e conteúdos.

5) Microinformática: composto por equipamentos e internet.

6) Outras saídas: boate, danceteria, zoológico etc.

Além desses, foram considerados o consumo de bens e serviços recreativos e culturais das famílias e as despesas com recreação e cultura, delimitados pela POF: despesas com brinquedos e jogos, celular e acessórios (aparelhos e acessórios de telefonia celular), recreações e esportes (cinema, teatro, futebol, ginástica etc.), instrumentos musicais, equipamentos esportivos, artigos de acampamento e demais despesas similares.

\subsection{Mensuração do índice de capital cultural}

Para mensuração do nível de capital cultural, foram usadas as proposições de Holt (1998) do Índice de Capital Cultural, obtido a partir da escolaridade e profissão dos indivíduos em uma família. Holt (2010), com base em critérios desenvolvidos por Bourdieu, estabeleceu um ranking de pontuação específica para cada nível de escolaridade e ocupação, como mostrado no Quadro 1. Nessa visão, entende-se que, quanto maior o grau de escolaridade das pessoas em uma família, maior o índice de capital cultural e maior o número 
de determinadas profissões que exigem maior grau de conhecimento e geram capital cultural maior.

Quadro 1 - Ranking de pontuação de capital cultural

\begin{tabular}{|l|c|}
\hline ESCOLARIDADE & ESCALA \\
\hline Até o ensino médio & 1 \\
\hline Superior concluído & 2 \\
\hline Pós-graduação & 3 \\
\hline Mestrado & 4 \\
\hline Doutorado/Ph.D. & 5 \\
\hline OCUPAÇÃO/PROFISSÃO & 1 \\
\hline Trabalho manual & 2 \\
\hline Serviço sem qualificação/Dona de casa & 3 \\
\hline Vendedor/Técnico/Comerciante & 4 \\
\hline Técnico especializado/Gestor/Professor & 5 \\
\hline Produtor cultural & \\
\hline
\end{tabular}

Fonte: HOLT, 2010.

Para obter o indicador parcial da Ocupação/Profissão, utilizou-se a função "SE" do Microsoft Excel para agrupar as profissões, com base nos códigos de ocupação descritos no documento Classificações POF 2008-2009. A função "SE" é uma das funções lógicas para retornar a um valor se uma condição for verdadeira e a outro valor se for falsa. Posteriormente, fazendo uso dessa mesma função, os agrupamentos de ocupações criados foram enquadrados na escala de Holt (2010). A partir desse enquadramento, aplicaram-se as notas a cada agrupamento de Ocupação/Profissão, conforme a escala constante no Quadro 1.

O Índice de Capital Cultural foi obtido a partir do somatório das notas dadas a cada indivíduo, seguindo-se o modelo descrito no Quadro 1. O índice de capital cultural foi, então, o somatório das notas da escolaridade e da profissão do chefe da família e do seu cônjuge. Para validar o construto Capital Cultural, utilizou-se o coeficiente Alpha de Cronbach, que é a estatística empregada para medir o grau de confiabilidade de uma escala. Esse coeficiente deverá estar acima de 0,6, conforme orientações de Hair Junior et al. (2005).

\subsection{Análise dos dados}

Para resolução do objetivo proposto neste trabalho, foi utilizada a técnica estatística de regressão linear múltipla, que é uma técnica multivariada usada com o objetivo de obter relação matemática entre uma das variáveis estudadas (variável dependente) e outras que descrevem o sistema, chamadas de independentes ou explicativas (HAIR JUNIOR et al., 2005). Neste estudo, pretendeu-se prever uma relação funcional entre uma variável dependente e o gasto com bens culturais, a partir do conhecimento de outras variáveis independentes. Segundo Hair Junior et al. (2005) e Cunha e Coelho (2011), a regressão linear múltipla é ferramenta robusta quando se tem o interesse em verificar a relação entre uma única variável dependente e duas ou mais independentes. Segundo Cunha e Coelho (2011) e Missio e Jacobi (2007), é possível incluir na análise de regressão variáveis não métricas como variáveis dependentes diretamente no modelo, indicando a presença de qualidade influenciadora da variável dependente. Para esse intuito, é necessário criar variáveis dammy, também chamadas de binárias ou categóricas. 
A variável dependente nesta pesquisa representa o gasto com bens culturais e será mensurada como o somatório de todas as despesas das famílias com esses bens, sendo, assim, uma variável métrica. As variáveis independentes métricas foram: idade (pessoa de referência, cônjuge), número de pessoas na família, renda familiar per capita e capital cultural; e as não métricas (dammy): sexo (pessoa de referência da família e do cônjuge) e cor (pessoa de referência, cônjuge).

A fim de chegar à melhor explicação para o modelo de regressão que elucida da melhor maneira possível a relação entre despesa e as variáveis independentes, utilizou-se o método Stepwise. Este método foi proposto por Cunha e Coelho (2011), encontrado no software SPSS 19.0, para fazer a regressão múltipla passo a passo, em que essas variáveis são incluídas e excluídas até se chegar ao melhor modelo final que explique melhor a relação entre elas.

Stepwise é um método de seleção passo a passo, em que todas as variáveis do modelo de regressão são previamente verificadas pelas suas estatísticas $\mathrm{F}$ parciais. A regressão Stepwise requer dois valores de corte: $F_{\text {in }}$ - de entrada e $F_{\text {out }}$ - de saída. Uma variável adicionada ao modelo no passo anterior pode ser redundante por causa do seu relacionamento com as outras variáveis; se sua estatística $\mathrm{F}$ parcial for menor que $F_{\text {out }}$, ela será removida do modelo (ACTION, 2013).

Os valores de $F_{\text {in }}$ e de $F_{\text {out }}$ são determinados pelo pesquisador a partir do nível de significância $(\alpha)$ crítico. E essa escolha vai depender do rigor que ele deseja para o seu modelo. Neste trabalho, utilizaram-se $F_{\text {in }}=0,05$ e $F_{\text {out }}=0,10$, por entender que a inclusão deve ser mais rigorosa que a exclusão, visto que, para fazer parte do modelo, a variável independente deve ter boa correlação com a variável dependente.

\section{RESULTADOS E DISCUSSÃO}

Nesta seção, apresentam-se os resultados das análises feitas a partir dos dados da POF. Primeiro, é mostrada a caracterização do perfil da amostra pesquisada, logo após vêm os procedimentos de validação Índice de Capital Cultural, passando depois para a análise de Regressão Linear Múltipla e, por último, finaliza com as conclusões.

\subsection{Caracterização geral da amostra}

Este estudo englobou 27.479 domicílios, com uma média de 4,25 pessoas em cada um, sendo 34,5\% deles localizados nos Estados da Região Nordeste e $24,1 \%$ na Região Sudeste. A renda per capita anual foi de $\mathrm{R} \$ 7.825,85$ e o gasto médio anual com bens culturais, de $\mathrm{R} \$ 6.752,70$. Em relação ao perfil da pessoa de referência, $88,8 \%$ eram homens de cor parda $(50,2 \%)$ com idade média de 43,98 anos e 6,81 anos de estudo, tendo a maioria $(70,4 \%)$ o ensino fundamental e a grande minoria $(1,4 \%)$, o mestrado e, ou, o doutorado. Seus cônjuges $(88,8 \%)$ eram mulheres de cor parda $(59,9 \%)$ com idade média de 40,6 anos e 7,5 anos de estudo, possuindo a maioria $(68,4 \%)$ o ensino fundamental e uma grande minoria $(1,4 \%)$, o mestrado e, ou, o doutorado.

Quanto à profissão, as pessoas de referência foram, em sua maioria, classificadas, para fins do cálculo do capital social, no grupo Vendedor/Técnico/Comerciante e os cônjuges, nos grupos Serviço sem qualificação/Dona de casa e Vendedor/Técnico/Comerciante. 


\section{2 Índice de capital cultural}

Seguindo as proposições de Holt (2010) descritas na metodologia, foi feito o cálculo do índice capital cultural para a amostra selecionada. Na Tabela 1 é apresentado o índice do capital cultural da amostra e também de cada região geográfica do país. Esse índice poderia variar entre 4 (valor mínimo) e 20 (valor máximo).

Nota-se, nessa tabela, um valor muito baixo do índice de capital cultural $(6,95)$. Isso se deve ao baixo nível de escolaridade e de profissões que exigem menos qualificação profissional imputada à amostra selecionada. O capital cultural mostrou-se correlacionado com a quantidade de anos de estudos da pessoa de referência $(r=0,52)$ e do cônjuge $(r=$ $0,51)$, evidenciando que, quanto maior a quantidade de anos de estudos, maior o capital cultural do indivíduo.

Tabela 1 - Comparação do Índice de Capital Cultural por região geográfica

\begin{tabular}{lccccccc}
\hline \multirow{2}{*}{ Região } & & & & \multicolumn{2}{c}{ Intervalo de Confiança } & & \\
\cline { 5 - 7 } & Norte & Média & Desvio-padrão & Limite inferior & Limite superior & Mínimo & Máximo \\
\hline Nordeste & 4099 & 6,81 & 3,15 & 6,71 & 6,91 & 4 & 20 \\
\hline Sudeste & 6493 & 6,41 & 3,04 & 6,35 & 6,47 & 4 & 20 \\
\hline Sul & 3409 & 7,36 & 3,49 & 7,27 & 7,44 & 4 & 20 \\
\hline Centro-Oeste & 3862 & 7,35 & 3,48 & 7,28 & 7,52 & 4 & 20 \\
\hline Total & 27479 & 6,95 & 3,32 & 7,24 & 7,46 & 4 & 20 \\
\hline
\end{tabular}

Fonte: Dados da pesquisa.

A validade do construto capital cultural foi avaliada por meio do coeficiente Alpha de Cronbach, a partir da escala de pontuação de Holt (2010) para escolaridade e profissão da pessoa de referência e do seu cônjuge. A medida do coeficiente de Alpha foi 0,82, acima do 0,6 estabelecido como limite para uma boa confiabilidade, o que indica a validade da escala para medir o construto capital cultural.

\subsection{Relação entre despesa com bens culturais, capital cultural e as variáveis sociodemográficas}

A análise de regressão foi utilizada com o objetivo de identificar a relação funcional entre a despesa anual com Bens e Serviços Culturais (variável dependente) e as variáveis independentes: o capital cultural e as variáveis sociodemográficas, verificando quais delas explicam melhor essas despesas e mostrando quais das variáveis exercem maior influência nos gastos com bens e serviços culturais. A partir do modelo Stepwise descrito nos procedimentos metodológicos, chegou-se a quatro modelos de regressão (Tabela 2).

Tabela 2 - Sumário dos modelos de regressão múltipla

\begin{tabular}{cccccc}
\hline Modelo & $\mathbf{R}$ & $\mathbf{R 2}$ & $\mathbf{R 2}$ ajustado & Erro-padrão & P-valor \\
\hline 1 & 0,6 & 0,36 & 0,36 & $11.611,91$ & 0,000 \\
\hline 2 & 0,61 & 0,37 & 0,37 & $11.503,38$ & 0,000 \\
\hline 3 & 0,62 & 0,38 & 0,38 & $11.386,89$ & 0,000 \\
\hline 4 & 0,62 & 0,38 & 0,38 & $11.374,77$ & 0,000 \\
\hline
\end{tabular}

Fonte: Dados da pesquisa. 
Constata-se nos indicadores a superioridade do modelo final (modelo 4) com quatro variáveis, visto que este modelo apresentou melhor $\mathrm{R}^{2}$ ajustado $(0,38)$, ou seja, o conjunto das quatro variáveis independentes explica $38 \%$ da alteração da variável dependente (despesas com bens e serviços culturais). O teste de $\mathrm{F}$ apresentou p-valor 0,000 , que é menor que o nível de significância de $0,05 \%$; nesse caso, rejeita-se a hipótese de que o $\mathrm{R}^{2}$ é igual a zero (Cunha e Coelho, 2005), ou seja, pode-se afirmar que pelo menos uma das variáveis independentes exerce influência sobre o consumo de bens e serviços culturais pelas famílias nucleares brasileiras.

Pela análise do modelo descrito na Tabela 3, foi obtida uma equação relacionada a despesas com bens e serviços culturais, todas elas com coeficientes positivos, indicando que estão positivamente relacionadas com a variável dependente. A constante (intercepto) deu valor negativo, mostrando que, se a renda familiar per capita, o número de pessoas no domicílio, o capital cultural e a idade do cônjuge fossem perto de zero, os seus gastos com consumo dos bens culturais seriam negativos. Na prática, essa situação seria difícil de acontecer, mas indica alguns questionamentos do tipo "como uma família com renda muito baixa e capital cultural baixo tenderia a um desequilíbrio nas despesas?".

Uma boa ideia da importância do poder das variáveis independentes em explicar a variável dependente é verificar o coeficiente padronizado ( $\beta=$ beta). Dessa forma, analisando a Tabela 3, observa-se, por esse coeficiente, que a variável Renda Per Capita Anual é a que mais explica os gastos com bens e serviços culturais, ou seja, tem maior peso $(0,54)$ nas despesas, seguida do número de pessoas no domicílio e do capital cultural. E a que menos explicou foi a variável Idade do Cônjuge, com beta 0,04. Todavia, todas as quatro variáveis estão positiva e significativamente relacionadas aos dispêndios com bens culturais. Assim, pode-se dizer que essas variáveis influenciam positivamente no aumento dos gastos, em que maior renda per capita, maior número de pessoas no domicílio, maior capital cultural e a idade do cônjuge levam as famílias a gastarem mais com bens e serviços culturais.

Tabela 3 - Coeficientes da Equação de Regressão Múltipla

\begin{tabular}{|c|c|c|c|c|c|c|c|}
\hline \multirow{2}{*}{ Modelo } & \multicolumn{3}{|c|}{ Coeficientes } & \multicolumn{4}{|c|}{ Colinearidade } \\
\hline & B & Erro-padrão & ( $\beta$ ) Beta & $\mathbf{t}$ & Sig. & Tolerance & VIF \\
\hline Constante & $-10,018,1$ & 376,38 & & $-26,6$ & 0,00 & & \\
\hline Renda per capita anual & 0,7 & 0,01 & 0,54 & 95,0 & 0,00 & 0,69 & 1,4 \\
\hline $\mathrm{N}^{\circ}$ de pessoas no domicilio & $1,268,5$ & 50,15 & 0,12 & 25,3 & 0,00 & 0,95 & 1,1 \\
\hline Capital cultural & 624,4 & 24,95 & 0,14 & 25,0 & 0,00 & 0,68 & 1,5 \\
\hline Idade do cônjuge & 42,8 & 5,54 & 0,04 & 7,7 & 0,00 & 0,90 & 1,1 \\
\hline
\end{tabular}

Fonte: Dados da pesquisa.

Outra consideração a ser feita é que as quatro variáveis do modelo não apresentaram problemas de multicolinearidade, de modo que cada variável explicou diferentes parcelas da variação da despesa com bens e serviços culturais. Os testes de Tolerance e Fator de Inflação da Variância (sigla em inglês - VIF) estão dentro do aceitável, conforme as orientações de Hair Junior et al. (2005) e Cunha e Coelho (2011), em que no Tolerance a multicolinearidade entre 1 e 0,10 é aceitável e no VIF, entre 1 e 10, que é o caso deste estudo, conforme se verifica na Tabela 3 . 
As outras variáveis incluídas na análise de regressão não foram inseridas no modelo por não apresentarem coeficientes significativos, sendo excluídas do modelo. São elas: idade da pessoa de referência, sexo da pessoa de referência (Dammy), sexo do cônjuge, cor da pele da pessoa de referência e do cônjuge e anos de estudo da pessoa de referência e do cônjuge.

\subsection{Discussão dos resultados}

Das variáveis demográficas escolhidas neste trabalho, somente a renda per capita familiar, o número de pessoas no domicílio e a idade do cônjuge, bem como o capital cultural, obtiveram relacionamento positivo com as despesas. A influência da renda no consumo de bens culturais foi verificada nos estudos de Diniz e Machado (2011) e Seiblitz, Bonifácio e Ayres (2013). Essa variável indica que a posição social da família tem impacto nos gastos com bens e serviços culturais. Diniz e Machado (2011) explicam que famílias mais abastadas tendem à maior exposição a bens artístico-culturais, devido às práticas individuais e, ou, familiares, melhorando, assim, o acesso a esses bens.

O número de pessoas no domicílio foi uma variável não encontrada nos estudos referenciados neste trabalho. Mas há uma lógica na relação dessa variável com os gastos, visto que, quanto mais pessoas há dentro de um domicílio, os gastos tendem a ser maiores. Dessa maneira, uma família (com características semelhantes) de três pessoas tende a gastar menos que uma de cinco. Os dados aqui apresentados confirmam essa lógica. Com base nesse achado, pode-se fazer a seguinte proposição: quanto maior o número de pessoas no domicílio, maior o gasto com bens e serviços culturais pelas famílias brasileiras.

Em relação à idade do cônjuge, verifica-se que ela tem relação com o aumento dos gastos com bens e serviços culturais. Essa informação está de acordo com a proposição de Diniz e Machado (2011) de que as características individuais, como a idade, influenciam o consumo de bens culturais. Com o aumento da idade, a demanda do consumidor pode mudar ao longo do tempo, devido à acumulação de capital humano, o que levaria à maior procura por bens culturais.

A busca da relação do capital cultural da família com as despesas com bens e serviços culturais foi um dos objetivos deste trabalho. Essa relação mostrou-se positiva e significativa dentro do modelo de regressão proposto. Tal verificação é semelhante à encontrada por Ponte e Mattoso (2014), que evidenciaram forte relação entre o nível de capital cultural de mulheres de classe média do Rio de Janeiro e o seu consumo de produtos culturais.

Duas proposições da Teoria do Capital Cultural puderam ser evidenciadas neste estudo e tiveram relação com o gasto com bens e serviços culturais pelas famílias. Segundo Diniz e Machado (2011), a educação é elemento essencial do capital cultural, uma vez que contribui para a competência de uma pessoa para aquisição e processamento de informações. Assim, aqueles que têm maior capital cultural e acessam essas informações terão maior valor e mais distinção, assim como acesso facilitado a outros recursos, como bens e serviços culturais. Sullivan (2001) argumentou que a posse de capital cultural varia de acordo com a classe social.

Nesse sentido, o fato de a renda e o capital cultural estarem correlacionados positivamente com as despesas com bens culturais reafirma esses pressupostos. A renda é um indicador da classe social e a educação, um dos componentes para o cálculo do índice de capital cultural. Assim, famílias com maior nível educacional terão capital cultural maior e também renda maior, visto que há correlação positiva entre nível educacional e renda, conforme relatou Luiz (2008). Essa relação foi evidenciada neste estudo, em que se verificou correlação positiva entre capital cultural das famílias, renda per capita das famílias $(r=0,497)$ e anos de estudos da pessoa de referência $(r=0,532)$ e do cônjuge $(r=0,517)$, todas essas variáveis são significativas a 0,01 e 99\% de confiança. 


\section{CONSIDERAÇÕES FINAIS}

O objetivo deste trabalho foi verificar a relação entre variáveis sociodemográficas e o capital cultural das famílias nucleares brasileiras com as despesas relacionadas ao consumo de bens e serviços culturais. Os resultados evidenciaram relação positiva entre a renda per capita familiar, o número de pessoas na família, o capital cultural e a idade do cônjuge com os gastos na aquisição de bens e serviços culturais, conforme o modelo de regressão proposto. A renda per capita foi a principal variável explicativa desses gastos, e a família com maior renda gasta mais do que as com renda menor. Concluiu-se, também, que os produtos culturais utilizados variavam conforme o maior ou menor capital cultural das famílias, evidenciando o fator educação como fonte de acesso a informações que auxiliam na busca por produtos e serviços culturais.

O conceito de capital proposto neste trabalho tem como premissa que indivíduos mais escolarizados possuem vantagens em relação ao acesso aos bens e serviços culturais. O capital cultural está ligado aos níveis educacional e de renda da família e estes, à classe social à qual essa família pertence. Assim, o consumo de bens culturais conserva relações associadas com as desigualdades sociais e culturais. $\mathrm{O}$ fato de uma família não ser dotada de recursos e de capital cultural implica maior possibilidade de desapossamento do gosto e do habitus de consumo de certos bens de cultura.

Reflexão sobre os resultados é de que estes são indicadores de desigualdade do consumo de bens e serviços culturais no Brasil, visto que famílias com renda e capital cultural mais elevados terão mais acesso a esse consumo do que as menos abastadas e com menor nível educacional. Destarte, políticas com o intuito de aumentar o acesso e viabilizar a oferta de bens e serviços culturais para as classes sociais mais baixas se fazem importantes para a diminuição dessa desigualdade, principalmente aquelas que não geram despesas para as famílias, como shows, teatros, cinema, festivais levados, de forma gratuita, para regiões carentes deste tipo de evento por órgãos competentes do governo, em níveis federal, estadual e municipal.

Entre as limitações deste estudo, ressalta-se o recorte temporal da base utilizada para análise dos dados (POF, 2008/2009), que reflete um comportamento passado dos consumidores. Essa limitação se deve ao fato de não haver até o momento uma POF mais atual. Nesse sentido, sugere-se que um novo estudo seja realizado com o mesmo intuito, ou seja, verificar as relações evidenciadas neste estudo que ainda permanecem, visto que o Brasil já passou por várias mudanças que podem ter alterado o comportamento dos consumidores. Além disso, verificou-se também a existência de diferenças entre regiões geográficas em relação ao índice de capital cultural.

Assim, seria interessante um estudo buscando relacionar o capital cultural das famílias com o consumo de bens e serviços culturais nas cinco regiões brasileiras, para verificar se o capital cultural é determinante dessas diferenças ou se existem outros fatores relacionados. 


\section{REFERÊNCIAS}

ARBIX, Glauco; ZILBOVICIUS, Mauro; ABRAMOVAY, Ricardo. Razões e ficções do desenvolvimento. São Paulo: Editora UNESP, 2001.

ALMEIDA CUNHA, Maria Amália de. O conceito "capital cultural" em Pierre Bourdieu e a herança etnográfica. Perspectiva, v. 25, n. 2, p. 503-524, 2007.

BOURDIEU, Pierre. O Capital Social: notas provisórias. In: NOGUEIRA, Maria Alice; CATANI, Afrânio. Escritos de Educação. Petrópolis: Vozes, 1998. p. 39-64.

CUNHA, Jacqueline Veneroso Alves da; COELHO, Antonio Carlos. Regressão Linear Múltipla. In: CORRAR, Luiz J; PAULO, Edilson; DIAS FILHO, José Maria (Org.). Análise Multivariada: para os cursos de Administração, Ciências Contábeis e Economia. São Paulo: Atlas, 2011. p. 131-231.

DINIZ, Sibelle Cornélio; MACHADO, Ana Flávia. Analysis of the consumption of artisticcultural goods and services in Brazil. Journal of Cultural Economics, v. 35, n. 1, p. 1-18, 2011.

HAIR JUNIOR, Joseph. F. et al. Fundamentos de Métodos de Pesquisa em Administração. Porto Alegre: Bookman, 2005.

HOLT, Douglas B. Does Cultural Capital Structure American Consumption. Journal of consumer research, vol. 37, june, 1998. Disponível em: http://www.jstor.org/discover/10.1086/209523?uid=2\&uid=4\&sid=21106063368751. Acesso 15 abril 2015.

HOLT, Douglas B. Toward a Theory of Status Consumption in Less Industrialized Countries. Journal of consumer research, vol. 37, june, 2010. Disponível em: http://www.jstor.org/discover/10.1086/649759?uid=2\&uid=4\&sid=21106063368751. Acesso 16 abril 2015.

LUIZ, Gilberto Venâncio. Consumo de Telefone Celular: Significados e Influências na Vida Cotidiana dos Adolescentes. 2008. 105 f. Dissertação (Mestrado) - Programa de Pósgraduação em Economia Doméstica, Departamento de Economia Doméstica, Universidade Federal de Viçosa, Viçosa, 2008.

MISSIO, Fabrício Missio; JACOBI, Luciane Flores. Variáveis dummy: especificações de modelos com parâmetros variáveis. Ciência e Natura, v. 29, n. 1, p. 111-135, 2007.

PAGLIOTO, Bárbara Freitas; MACHADO, Ana Flávia. Perfil dos frequentadores de atividades culturais: o caso nas metrópoles brasileiras. Estudos Econômicos (São Paulo), v. 42, n. 4, p. 701-730, 2012.

PINHEIRO, Luana Simões; FONTOURA, Natália de Oliveira. Perfil das despesas e dos rendimentos das famílias brasileiras sob a perspectiva de gênero. In: SILVEIRA, F. G.; SERVO, L. M. S.; ALMEIDA, T.; PIOLA, S. F. (Org.). Gastos e consumos das famílias brasileiras contemporâneas. Brasília: IPEA, 2007. 
PONTE, Lucivânia Filomeno; MATTOSO, Cecilia Queirós. Capital Cultural e o Consumo de Produtos Culturais: As Estratégias de Consumo de Status entre Mulheres da Nova Classe Média. Revista Brasileira de Marketing, v. 13, n. 6, p. 18-33, 2014.

PRIEUR, Annick; SAVAGE, Mike. Updating cultural capital theory: A discussion based on studies in Denmark and in Britain. Poetics, v. 39, n. 6, p. 566-580, 2011.

ROYAL, Jan. Evaluating human, social and cultural capital in nurse education. Nurse education today, v. 32, n. 5, p. 19-22, 2012.

SEIBLITZ, Dayana Mattos de Lossio E.; BONIFÁCIO, Andréa Soares; AYRES, Andreia Ribeiro. Um Olhar Sobre o Consumo Brasileiro de Bens e Serviços Recreativos e Culturais. Polêmica, v. 12, n. 4, p. 764-777, 2013.

SILVA, Frederico Barbosa da; ARAÚJO, Herton Ellery; SOUZA, André Luis. O consumo cultural das famílias brasileiras. In: SILVEIRA, F. G. et al (Orgs.). Gasto e consumo das famílias brasileiras contemporâneas. Brasília: IPEA, 2007.

SILVA, Áurio Lúcio Leocadio da. Consumo de produtos culturais em São Paulo: análise dos fatores antecedente e proposta de modelo. São Paulo: USP, 2008. 210 p. Tese (doutorado) Programa de pós-graduação em administração, Universidade de São Paulo, São Paulo, 2008.

SUlliVAN, Alice. Cultural capital and educational attainment. Sociology, v. 35, n. 04, p. 893-912, 2001. 